\title{
Is iron overload a risk factor for mycobacterium tuberculosis and a potential target of therapy?
}

\begin{abstract}
Mycobacterium TB infection remains a significant global health problem. The increase in resistant forms of TB to once effective antibiotics has called for improved understanding of the organism's metabolism and host response to help develop new therapeutic strategies. Clinical observations have identified patients with iron overload that are at higher risk for mycobacterium tuberculosis and may have a greater risk of mortality. Understanding mechanisms of iron homeostasis have led to important experiments addressing the pathogenicity of mycobacterial species. Conditions that favor high iron concentrations serve to promote mycobacterial growth and render a survival advantage for the pathogen. Iron trafficking in the host is a complex process but serves as an important feature in the host immune response. In-vitro studies demonstrate Siderocalin molecules interfere with the function of pathogenic siderophores and inhibit the growth of mycobacterium tuberculosis. Thus, exciting therapeutic opportunities exist in the potential targeting of siderophores. In addition determining patient-specific hepcidin activity may be useful in ascertaining risk for mycobacterial infection in endemic regions.
\end{abstract}

Volume 4 Issue 6 - 2017

\section{Kamal Shemisa}

Department of Internal Medicine, University of Texas Southwestern Medical, USA

Correspondence: Kamal Shemisa M.D., UT Southwestern Department of Internal Medicine, Division of Internal Medicine, USA, Tel (262) 364-7919, Email kshemisa@neomed.edu

Received: April 14, 2017 | Published: May 05, 2017

\section{Introduction}

Infections due to mycobacterium tuberculosis remain a significant global health problem. The WHO (World Health Organization) estimated that TB remains one of the top ten causes of death worldwide, accounting for roughly 1.37 million deaths in 2015 alone. TB is treatable however drug resistant forms to rifampin as well as multi and extensively drug resistant strains are growing at a significant rate. The success rate of treating MDR and XDR is lower than susceptible forms with a rate of $48 \%$ and $29 \%$ respectively. ${ }^{1}$ In addition the rise in incidence of non-tuberculous mycobacterium in patients who are immunocompromised and in vulnerable populations such as sickle cell disease by mycobacterium avium and mucogenicum infections are reported. ${ }^{9}$ Both organisms require similar prolonged durations of therapy as with mycobacterium tuberculosis although the reported resistance is lower. It is therefore relevant to discuss potential alternative strategies to address the burden associated with these drug resistant forms of mycobacteria. Before we can do so, understanding the basis of virulence of mycobacterium infection and the immune response is necessary. In the subsequent descriptions of TB and non-tuberculous mycobacterium I will refer to both as mycobacterium and mycobacterial diseases for ease of description. We will predominantly focus on the clinical observations which

Table I Risk of mycobacterium tuberculosis infection in cohorts with exposure of high total body iron concentration

\begin{tabular}{|c|c|c|c|c|}
\hline Patient population & Exposure & Iron content marker & Outcome & Implications \\
\hline $\begin{array}{l}\text { Smokers and } \\
\text { nonsmokers who } \\
\text { underwent }\end{array}$ & Smoking & $\begin{array}{l}\text { Higher iron content in } \\
\text { broncho-alveolar }\end{array}$ & $\begin{array}{l}\text { Lower transferrin concentrations } \\
\text { in }\end{array}$ & $\begin{array}{l}\text { Smoking status maybe related to } \\
\text { increased }\end{array}$ \\
\hline \multirow[t]{2}{*}{ broncho-alveiolar lavage. } & & macrophages & $\begin{array}{l}\text { patients with chronic obstructive } \\
\text { pulmonary disease. }\end{array}$ & $\begin{array}{l}\text { risk for mycobacterium tuberculosis } \\
\text { although observational studies } \\
\text { confirming }\end{array}$ \\
\hline & & & $\begin{array}{l}\text { Symptomatic smokers had a } 4.5- \\
7 \text { fold greater iron concentration } \\
\text { than nonsmokers. }\end{array}$ & this association are lacking. \\
\hline $\begin{array}{l}\text { Necropsy specimens of } \\
\text { patients who died }\end{array}$ & Iron overload & $\begin{array}{l}\text { High concentration of } \\
\text { iron in spleens. }\end{array}$ & $\begin{array}{l}\text { In patients that died of } \mathrm{TB} \text {, there } \\
\text { were }\end{array}$ & $\begin{array}{l}\text { Iron overload maybe a strong risk } \\
\text { factor }\end{array}$ \\
\hline
\end{tabular}

have led to the discovery of important pathways in iron trafficking and further discuss the therapeutic implications in the treatment of mycobacterium tuberculosis.

\section{Clinically derived association of high total body iron and risk of mycobacterium tuberculosis infection}

Clinical observations have found that exposures linked to high iron states maybe important risk factors for mycobacterium infection such as TB (Table 1). Patients diagnosed with iron overloaded (i.e. high macrophage iron content), quantified by measuring splenic iron post necropsy, were associated with a 17 fold greater odds of mycobacterial tuberculosis infection and possibly death. ${ }^{2}$ The implications of mycobacterium infection due to an iron rich environment in those with chronic obstructive pulmonary disease who are smokers raise the possibility of an underappreciated risk factor for development of pulmonary TB. ${ }^{3}$ Lastly a case control study from Zimbabwe demonstrated that increased dietary iron from local beer consumption was associated with a 3.5 fold increase in mycobacterial tuberculosis, higher indices for total body iron, and 1.3 fold increase in death after age and sex adjustment. ${ }^{4}$ Lastly genetic polymorphisms in hepcidin demonstrated differing functionality in iron handling and patients diagnosed with pulmonary TB were found to have 3.1 fold greater odds of (2-4.8) of G allele hepcidin polymorphisms. ${ }^{5}$ 
Table continued..

\begin{tabular}{|c|c|c|c|c|}
\hline Patient population & Exposure & Iron content marker & Outcome & Implications \\
\hline of Tuberculosis & & & $\begin{array}{l}\text { I } 6.9 \text { fold greater odds of } \\
\text { elevated splenic iron } 2\end{array}$ & $\begin{array}{l}\text { for risk of death to mycobacterial } \\
\text { tuberculosis. }\end{array}$ \\
\hline \multirow{4}{*}{$\begin{array}{l}\text { Patients with } \\
\text { pulmonary tuberculosis }\end{array}$} & $\begin{array}{l}\text { determined by beer } \\
\text { consumption }\end{array}$ & Serum Ferritin: & $\begin{array}{l}\text { with } 3.5 \text { fold increase of } \\
\text { mycobacterial tuberculosis and } \\
\text { I. } 3\end{array}$ & $\begin{array}{l}\text { overload appears to confer increased } \\
\text { risk of infection among patients with }\end{array}$ \\
\hline & & Mean: $498 \mu \mathrm{g} / \mathrm{L}$ & $\begin{array}{l}\text { fold increase of death. This risk } \\
\text { increases }\end{array}$ & elevated ferritin and transferrin. \\
\hline & & Range: $152-1517 \mu g / L$ & substantially in HIV infection. & \\
\hline & & Serum Transferrin saturat & on: $43 \pm 21$ & \\
\hline \multirow[t]{2}{*}{$\begin{array}{l}\text { Patients with } \\
\text { tuberculosis }\end{array}$} & $\begin{array}{l}\text { G allele Hepcidin } \\
\text { polymorphism }\end{array}$ & $\begin{array}{l}\text { Serum Iron: } 53.5 \pm 16.2 \\
\mu g / d L\end{array}$ & $\begin{array}{l}\text { Compared to controls, patients } \\
\text { with TB }\end{array}$ & $\begin{array}{l}\text { Maybe a prognostic marker in } \\
\text { patients }\end{array}$ \\
\hline & & & G allele hepcidin polymorphisms & a therapeutic option. \\
\hline
\end{tabular}

Mediators of Iron trafficking and their potential role in understanding the immune response against mycobacterial infection

The immune system currently combats mycobacterial infections via advanced cytokine responses which trigger innate, cell mediated and humoral immunity. The major antimicrobial mechanisms that target mycobacterial infections include macrophage mediated phagocytosis, T-cell mediated sensitization via CD4 T-helper cells thus promoting granuloma formation. ${ }^{6}$ Indeed patients who are immunocompromised such as in untreated HIV are susceptible to mycobacterial infections for this reason. Disease transmission and pathogenesis varies depending on the specific characteristics of the host and the species of mycobacterium (Table 2).

Table 2 Iron trafficking mediators and conditions associated with the inhibition and promotion of growth of mycobacterium tuberculosis

\begin{tabular}{lll}
\hline & $\begin{array}{l}\text { Inhibits } \\
\text { growth of } \\
\text { mycobacterium } \\
\text { tuberculosis }\end{array}$ & $\begin{array}{l}\text { Promotes } \\
\text { Growth of } \\
\text { Mycobacterium } \\
\text { tuberculosis }\end{array}$ \\
\hline TfR (transferrin) & Yes & No \\
Beta-2 microglobulin & Yes & No \\
HFE (Class I MHC) & Yes & No \\
Hepcidin & Yes & no \\
Iron Rich environment & No & Yes \\
Beta-2 microglobulin deficiency & No & Yes \\
HFE deficiency & No & Yes \\
Siderophores & No & Yes \\
Siderocalin & Yes & No \\
\hline
\end{tabular}

The process by which mycobacterium acquire iron from the host is complex and serves to promote organism growth and survival advantage. Not only is cell mediated immunity via phagocytosis of the organism necessary for successful elimination of mycobacterium but a mechanism of depriving mycobacterium from available iron molecules. Thus host mechanisms to limit iron acquisition by microorganisms involve the complex interaction of iron binding proteins such as TfR (transferrin receptor), beta-2 microglobulin and HFE as well as the up regulation of NRAP. In general surpluses of iron in vitro were found to further enhance the growth of mycobacterium tuberculosis. ${ }^{4}$ In response to infection, hepcidin which is intimately involved in the regulation of duodenal absorption of iron, is upregulated and binds to ferroportin leading to internalization and degradation of the protein thus limiting dietary iron absorption. Other mechanisms for iron acquisition include phagocytosis of red blood cells and extraction from hemoglobin. Once mycobacterium infect macrophages however the release of interferon gamma down regulates TfR and HFE genes in order to limit iron acquisition by phagocytosed mycobacterium. ${ }^{9}$

Mycobacterium is dependent on iron to activate promoters of vital genes and utilize iron for oxidative reactions including those involved in free radical formation or elimination. ${ }^{10}$ In response to the host mechanisms of iron sequestration, mycobacterium regulate gene expression of iron binding proteins. Like the host, Mycobacterial organisms are also adapted to acquire iron molecules in iron poor environments. Iron molecules $(\mathrm{Fe} 2+)$ bind to repressor proteins during iron rich states thus inhibiting the synthesis of siderophores. Repressor proteins dissociate from $\mathrm{Fe} 2+$ when iron is scarce which leads to transcription of the siderophores. Siderophores secreted by mycobacterium function as small, high-affinity iron-chelating compounds and bind the iron in the Fe3+ ion state. The siderophore$\mathrm{Fe} 3+$ complex is then taken up by the bacterium and upon entering the cytoplasm $\mathrm{Fe} 3+$ is converted to $\mathrm{Fe} 2+$, the active form. Therefore siderophore molecules used by mycobacterium for iron acquisition maybe good targets for treatment because the bacteria's survival and virulence is related to host iron availability. ${ }^{11}$

Exciting therapeutic opportunities exist in the potential targeting of siderophores. Small molecules called siderocalins that bind to siderophores as well as molecules that inhibit bacterial synthesis of siderophores are currently under investigation. ${ }^{12}$ Treatment of infected macrophages in vitro with siderocalin limits the replication of mycobacterium tuberculosis within the macrophage. ${ }^{13}$ The development of mycobactin siderophore analogues has similarly shown significant inhibition of mycobacterium tuberculosis growth. An alternative approach of treatment is gene manipulation through irreversible inhibition of iron dependent regulator protein (IdER). Activation of repressor protein of siderophore synthesis would be advantageous when the pathogen is iron deficient and depends on siderophore synthesis for survival. ${ }^{11}$ The role of hepcidin molecules in therapeutics is less certain however determining patient-specific 
hepcidin activity may be useful in ascertaining risk for TB in endemic regions.

\section{Conclusion}

Mycobacterial infections particularly TB remain a significant public health problem. The development of resistant forms of TB as well as the often long treatment durations of mycobacterial infection poses tremendous challenges for clinicians and calls for newer ways to risk stratify and develop alternative therapies to address these pathogens. Understanding mechanism of iron acquisition in the host and by mycobacterial organisms offer insights into the disease mechanism, risk for infection and potential targets of therapy.

\section{Acknowledgements}

None.

\section{Conflicts of interest}

There is no conflict of interest.

\section{Funding}

None.

\section{References}

1. Kim DH, Kim HJ, Park SK, et al. Treatment outcomes and survival based on drug resistance patterns in multidrug-resistant tuberculosis. Am J Respir Crit Care Med. 2010;182(1):113-119.

2. Gordeuk VR, McLaren CE, MacPhail AP, et al. Associations of iron overload in Africa with hepatocellular carcinoma and tuberculosis: Strachan's 1929 thesis revisited. Blood. 1996;87(8):3470-3476.

3. Mateos F, Brock JH, Perez Arellano JL. Iron metabolism in the lower respiratory tract. Thorax. 1998;53(7):594-600.
4. Gangaidzo IT, Moyo VM, Mvundura E, et al. Association of pulmonary tuberculosis with increased dietary iron. J Infect Dis. 2001;184(7):936939

5. Javaheri Kermani M, Farazmandfar T, Ajami A, et al. Impact of hepcidin antimicrobial peptide on iron overload in tuberculosis patients. Scand J Infect Dis. 2014;46(10):693-696.

6. Cooper AM. Cell-mediated immune responses in tuberculosis. Annu Rev Immunol. 2009;27:393-422.

7. Schaible UE, Collins HL, Priem F, et al. Correction of the iron overload defect in beta-2-microglobulin knockout mice by lactoferrin abolishes their increased susceptibility to tuberculosis. J Exp Med. 2002;196(11):1507-1513.

8. Gomes-Pereira S, Rodrigues PN, Appelberg R, et al. Increased susceptibility to Mycobacterium avium in hemochromatosis protein HFE-deficient mice. Infect Immun. 2008;76:4713-4719.

9. Shemisa K, Jafferjee N, Thomas D, et al. Mycobacterium avium Complex Infection in a Patient with Sickle Cell Disease and Severe Iron Overload. Case Rep Infect Dis. 2014:405323.

10. Talukdar D, Sharma R, Sharma AK, et al. Drug resistance in tuberculosis: how to counter the menace? Curr Pharm Biotechnol. 2014;15(12):11581165 .

11. Monfeli RR, Beeson C. Targeting iron acquisition by Mycobacterium tuberculosis. Infect Disord Drug Targets. 2007;7(3):213-220.

12. Ferreras JA, Ryu JS, Di Lello F, et al. Small-molecule inhibition of siderophore biosynthesis in Mycobacterium tuberculosis and Yersinia pestis. Nat Chem Biol. 2005;1(1):29-32.

13. Erin E Johnson, Chittur V Srikanth, Andreas Sandgren, et al. Siderocalin inhibits the intracellular replication of Mycobacterium tuberculosis in macrophages. FEMS Immunol Med Microbiol. 2010;58(1):138-145. 